\title{
Real-time quantitative PCR with SYBR Green I detection for estimating copy numbers of nine drug resistance candidate genes in Plasmodium falciparum
}

\author{
Isabel D Ferreira1 ${ }^{1}$, Virgílio E do Rosário ${ }^{1}$ and Pedro VL Cravo*2
}

\begin{abstract}
Address: ${ }^{1}$ Centro de Malária e Outras Doenças Tropicais/IHMT/UNL, Rua da Junqueira, 96, 1349-008, Lisbon, Portugal and ${ }^{2}$ Centro de Malária e Outras Doenças Tropicais/UEI Biologia Molecular/IHMT/UNL, Rua da Junqueira, 96, 1349-008, Lisbon, Portugal

Email: Isabel D Ferreira - ferreiraID@ihmt.unl.pt; Virgílio E do Rosário - cmdt@ihmt.unl.pt; Pedro VL Cravo* - pcravo@ihmt.unl.pt

* Corresponding author
\end{abstract}

Published: 18 January 2006

Malaria Journal 2006, 5:I doi:10.1186/1475-2875-5-I

This article is available from: http://www.malariajournal.com/content/5/I/I

(c) 2006 Ferreira et al; licensee BioMed Central Ltd.

This is an Open Access article distributed under the terms of the Creative Commons Attribution License (http://creativecommons.org/licenses/by/2.0), which permits unrestricted use, distribution, and reproduction in any medium, provided the original work is properly cited.
Received: 19 October 2005

Accepted: 18 January 2006

\begin{abstract}
Background: Evaluating copy numbers of given genes in Plasmodium falciparum parasites is of major importance for laboratory-based studies or epidemiological surveys. For instance, pfmdrl gene amplification has been associated with resistance to quinine derivatives and several genes involved in anti-oxidant defence may play an important role in resistance to antimalarial drugs, although their potential involvement has been overlooked.
\end{abstract}

Methods: The ${ }^{\Delta \Delta} \mathrm{Ct}$ method of relative quantification using real-time quantitative PCR with SYBR Green I detection was adapted and optimized to estimate copy numbers of three genes previously indicated as putative candidates of resistance to quinolines and artemisinin derivatives: pfmdrl, pfatp6 (SERCA) and pftctp, and in six further genes involved in oxidative stress responses.

Results: Using carefully designed specific RT-qPCR oligonucleotides, the methods were optimized for each gene and validated by the accurate measure of previously known number of copies of the pfmdrl gene in the laboratory reference strains P. falciparum 3D7 and Dd2. Subsequently, Standard Operating Procedures (SOPs) were developed to the remaining genes under study and successfully applied to DNA obtained from dried filter blood spots of field isolates of $P$. falciparum collected in São Tomé \& Principe, West Africa.

Conclusion: The SOPs reported here may be used as a high throughput tool to investigate the role of these drug resistance gene candidates in laboratory studies or large scale epidemiological surveys.

\section{Background}

In the absence of a viable vaccine, current methods used for the control of malaria invariably rely on prevention through minimizing exposure to mosquitoes, and drug treatment of clinical disease. In areas of high transmission, where large numbers of malaria cases are presently inevitable, there is a reliance on anti-malarial drugs to treat the disease. However, parasite resistance, especially of Plasmodium falciparum, has been recorded to every antimalarial drug currently in use [1].

It has been shown that differential copy numbers and/or differential transcription of putative drug resistance gene candidates may influence responses to drugs in malaria 
Table I: Genes analysed in this study

\begin{tabular}{|c|c|c|c|}
\hline Gene annotation & Abbreviation & Chromosome & Accession number \\
\hline actin (housekeeping) & $\beta$-actin I & 12 & NP_701803 \\
\hline multidrug resistance protein & $m d r l$ & 5 & NP_703574 \\
\hline calcium-transporting ATPase (SERCA) & atp6 & I & NP_703265 \\
\hline histamine-releasing factor, putative & tctp & 5 & NP_703454 \\
\hline glutathione peroxidase & $g p x$ & 12 & NP_70I484 \\
\hline glutathione reductase & $g r$ & 14 & NP_702080 \\
\hline glutathione S-transferase & gst & 14 & NP_702075 \\
\hline fe-superoxide dismutase & sodl & 8 & NP_704405 \\
\hline trx peroxidase (2-Cys peroxiredoxin) & $\operatorname{trx} l$ & 14 & NP_702257 \\
\hline thioredoxin peroxidase & $\operatorname{tr} x 2$ & 12 & NP_701510 \\
\hline
\end{tabular}

parasites. For instance, both in laboratory-adapted strains and clinical samples of $P$. falciparum increased copy numbers of the pfmdr1 gene have been implicated in resistance to quinine derivatives $[2,3]$. Additionally, changes in copy numbers of other genes, such as those coding for antioxidant defense enzymes, may be important in antimalarial drug resistance although these have not been fully explored as putative candidates $[2,4]$. In this context, is has been shown that higher levels of glutathione (GSH) in some parasites may help protect them from the toxic effects of chloroquine and thus contribute to resistance. Both in P. falciparum and in the rodent malaria parasite Plasmodium berghei, CQ-resistant lines contained higher levels of GSH than their sensitive counterparts [5], and this was related to increased expression of glutathione-stransferase (gst) [6,7]. In addition, other anti-oxidant stress genes such as thioredoxins, have been widely shown to confer resistance to artesunate in tumor cells [8], but these have scarcely investigated in the context of drugresistant malaria.

More recently, Uhlemann and colleagues provided strong evidence to indicate that resistance to artemisinins may depend on single nucleotide polymorphisms in the drug's putative chemotherapeutic target, the SERCA-type ATPase protein of $P$. falciparum (PfATP6) [9], although epidemiological evaluation of gene copy numbers in natural parasite populations has not been carried out.

Previous reports have described protocols for estimating copy numbers of the $p f m d r 1$, using real-time quantitative PCR (RT-qPCR) [10,11]. Although the methods were shown to be highly sensitive, the fluorescent PCR signal was detected with TaqMan or hybridization probes specific for the $m d r 1$ gene exclusively.

The objective of the present work was to develop protocols to estimate candidate gene copy numbers in genomic DNA extracted from dried blood spots of laboratoryadapted strains and field-collected isolates of $P$. falci- parum, using RT-qPCR with SYBR green I detection. The genes included in the study were chosen on the basis of either a previous involvement in antimalarial drug resistance or their involvement in parasite responses to antioxidant stress (Table 1). SYBR Green I fluorescent dye has the important property of being a sequence-independent, universal RT-qPCR detection system, due to its ability to bind to all dsDNA molecules. Therefore, when working with a large panel of genes, using SYBR green instead of probes is another way to meet the demand of high throughput and to work more cost effectively.

Although SYBR Green I detection is prone to lack of specificity, its comparative low price and ability to detect any given PCR product in a sequence-independent manner outweigh its potential disadvantages provided optimal conditions are assured.

\section{Methods DNA extraction from laboratory clones and field isolates of $P$. falciparum}

A set of eight DNA samples of $P$. falciparum from the Democratic Republic of Sao Tomé \& Principe (DRSTP) were used in this study. Blood samples had been collected previously by Passive Case Detection (PCD) as part of an ongoing collaboration between Portugal and the DRSTP during the month of February 2004, from suspected malaria carriers attending the Centro Policlínico de Saúde de Água Grande, in the city of São Tomé.

No age restrictions were applied. After confirmation of $P$. falciparum infection by microscopical observation of thin and thick Giemsa-stained blood films, $1 \mathrm{ml}$ of venous blood was collected into Monovettes containing EDTA, after individual informed consent and local ethical approval. A sub-sample of this was spotted onto Whatman $n^{\circ} 4$ filter paper and then parasite genomic DNA was obtained from all samples by boiling in Chelex-100 [12] followed by ethanol precipitation. A similar protocol was used to extract genomic DNA from the references strains 
Table 2: Real-time quantitative PCR primers

\begin{tabular}{|c|c|c|c|c|}
\hline Gene & Primer & Sequence $\left(5^{\prime} \Rightarrow 3^{\prime}\right)$ & Concentration (nm) & Amplicon size (bp) \\
\hline \multirow[t]{2}{*}{ Pf- $\beta$-actin I } & sense & GGA CAC ATA TTG TGC CTG C & 300 & 90 \\
\hline & antisense & CTC CAC TAT CTA ACA CAA TAC C & 300 & \\
\hline \multirow[t]{2}{*}{ Pf-mdrl } & sense & CAA GTG AGT TCA GGA ATT GGT AC & 300 & 230 \\
\hline & antisense & GCC TCT TCT ATA ATG GAC ATG G & 300 & \\
\hline \multirow[t]{2}{*}{ Pf-atp6 } & sense & GCT GCA TTC ATT AGT TTC GTG & 300 & 126 \\
\hline & antisense & GCC ATA CAC CTA CGG CAG C & 600 & \\
\hline \multirow[t]{2}{*}{ Pf-tctp } & sense & CAA ATG ATG AAG TAT GTT CCG & 300 & 55 \\
\hline & antisense & GGT ACT TCA AAT GGA TCT TGT TG & 600 & \\
\hline \multirow[t]{2}{*}{$P f-g p x$} & sense & CGT CGA TAA AAA TGG AGA AGT TG & 300 & 56 \\
\hline & antisense & CTA ACG GGT TTG TTT TGG GTG & 600 & \\
\hline \multirow{2}{*}{ Pf-gr } & sense & GCA GTG GCC TTA AAA ATG AAT G & 300 & 68 \\
\hline & antisense & GCT GTA GGA TGT ATA GGT ATG G & 300 & \\
\hline \multirow[t]{2}{*}{ Pf-gst } & sense & GAT GCA AGG GGT AAA GCT G & 300 & 150 \\
\hline & antisense & GGG TAC TTG CTC AAA AGG AG & 600 & \\
\hline \multirow[t]{2}{*}{ Pf-sodl } & sense & GAT TAC AGA AAT GAC AGA GCA TC & 300 & 56 \\
\hline & antisense & CAA TTT ACT AGG TTC CAC CAA G & 600 & \\
\hline \multirow[t]{2}{*}{ Pf-trxI } & sense & CAT ATG TAG GAA GAG AAG CTC C & 300 & 53 \\
\hline & antisense & ATC TGC AAA AAC TGC TTC AGC C & 600 & \\
\hline \multirow[t]{2}{*}{ Pf-trx2 } & sense & CGC TAG TGA CAA AGA AGG C & 300 & 60 \\
\hline & antisense & ACA AAC AAC AGT ATT TCT GAC C & 600 & \\
\hline
\end{tabular}

P. falciparum 3D7 and Dd2, which were kept in deep frozen stabilates and cultured in vitro at the time of these experiments.

\section{Oligonucleotide primer design}

Using data deposited in P. falciparum GeneDB [13], P. falciparum 3D7 individual cDNA gene sequences were retrieved and used as template for designing all real-time PCR oligos (Table 2).

Real-time PCR oligonucleotide primers were manually designed for each of the genes to assure maximal efficiency and sensitivity, according to the following parameters: avoidance of the formation of self and hetero-dimers, hairpins and self-complementarity, primer length and melting temperature. These properties were verified using two different internet-based interfaces: Primer-3 [14] and Oligonucleotide Properties Calculator [15]. When possible, "GC clamps" were placed at the 3'-end of each primer to minimize breathing between primer and template DNA, which can promote mispriming and decrease efficiency. Primers were designed such that amplicon sizes ranged between 50 and 250 bps. Melting curve analysis was always performed at the end of each PCR assay to control for specificity; specific reactions should result in a single melting peak corresponding to the PCR product being amplified. In contrast, multiple melting peaks imply that that the reaction is either unspecific in that it originates more than one amplicon or that primer dimers are being formed. Either condition alters the validity of PCR kinetic parameters and, thus, any primer pairs producing more than one melting peak were discarded.

\section{Real-time PCR assays}

Real-time PCR was performed in the GenAmp 5700 SDS $^{\circledast}$ (Applied Biosystems ${ }^{\mathrm{TM}}$ ), using the default thermocycler program for all genes: 10 minutes of pre-incubation at $95^{\circ} \mathrm{C}$ followed by 40 cycles for 15 seconds at $95^{\circ} \mathrm{C}$ and one minute at $60^{\circ} \mathrm{C}$.

Individual real-time PCR reactions were carried out in 20 $\mu \mathrm{l}$ volumes in a 96-well plate (Applied Biosystems ${ }^{\mathrm{TM}}$ ) containing $1 \times$ buffer $(10 \times), 3.5 \mathrm{mM} \mathrm{MgCl}{ }_{2}, 200 \mu \mathrm{M}$ dNTPs, different concentrations of sense and antisense primers (Table 2), $0.025 \mathrm{U} / \mu \mathrm{l}$ enzyme and 1:66000 SYBR GreenI ${ }^{\circledR}$. All reactions were made using $\mathrm{qPCR}^{\mathrm{TM}}$ Core Kit for SYBR Green I ${ }^{\circledast}$ (EUROGENTEC ${ }^{\mathrm{TM}}$ ).

At the end of each reaction, Cycle threshold (Ct) was manually setup at the level that reflected the best kinetic PCR parameters, and melting curves were acquired and analysed.

\section{Data analysis using the 2- $-\Delta \Delta \mathrm{Ct}_{\mathrm{t}}$ method and its validation}

The two most commonly used methods to analyse data from real-time, quantitative PCR experiments are absolute quantification and relative quantification. Absolute quantification is usually applied to determine the input copy number, usually by relating the PCR signal to a standard curve. Relative quantification is more commonly used to measure gene expression by relating the PCR signal of the target transcript in a treatment group to that of a sample such as an untreated control. Absolute quantification is usually more accurate but requires elaboration of standard curves for each gene under study that need be ran at 


\begin{tabular}{|cc|}
\hline Log [DNA] & Ct pfgr - Ct pfßactinl \\
0 & -3.6 \\
-1 & -3.9 \\
3 & -4.3 \\
-4 & -3.4 \\
5 & -3.9 \\
\hline
\end{tabular}

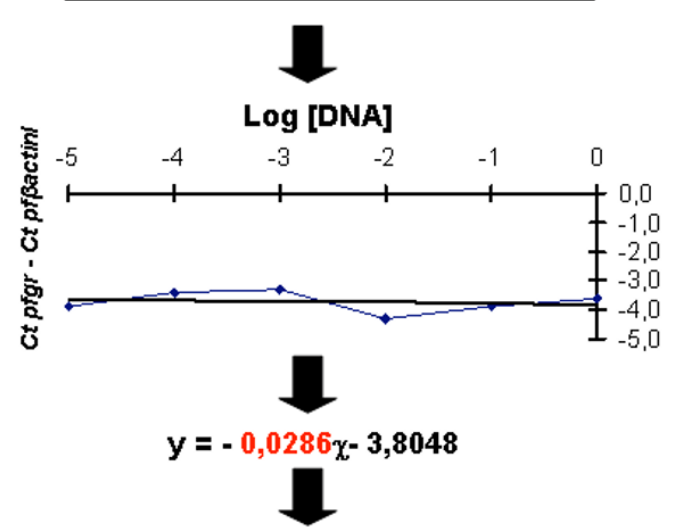

$|\mathrm{m}|=0.0286<0.1$ a

b

C

Figure I

Calculation of relative efficiency of the $P$. falciparum glutathione reductase gene (Pfgr). The average $C t$ at each dilution was calculated for both $P f$ - $\beta$-actin $I$ and the glutathione reductase gene, $P f g r$, and $\mathrm{Ct}, P f g r-\mathrm{Ct}, P$ - $\beta$-actin I was determined (a). Plots of the log DNA dilution versus $\Delta \mathrm{Ct}$ were made (b) and a slope was calculated from this (c). The absolute value of this slope $(\mathrm{m})$ was $0.0286(<0.1)(\mathrm{d})$, reflecting optimal relative efficiency.

each experiment, thus increasing experimental costs and significantly decreasing throughput.

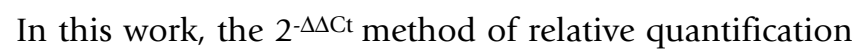
(described in detail in [16]) was adapted to estimate copy numbers in $P$. falciparum genes. This method allows to estimate gene copy numbers in unknown samples, requiring two main pre-requisites. The first is the existence of at least one calibrator consisting of template DNA with known copies of each of the studied genes. The second is the need to have a house-keeping gene of constant copy number in all samples, which permits normalization of the quantitative data. In this work, genomic DNA extracted from $P$. falciparum 3D7, known to harbour a single copy of each gene studied, was used as calibrator, while Pf- $\beta$-actin 1 served as the house-keeping gene in all experiments.

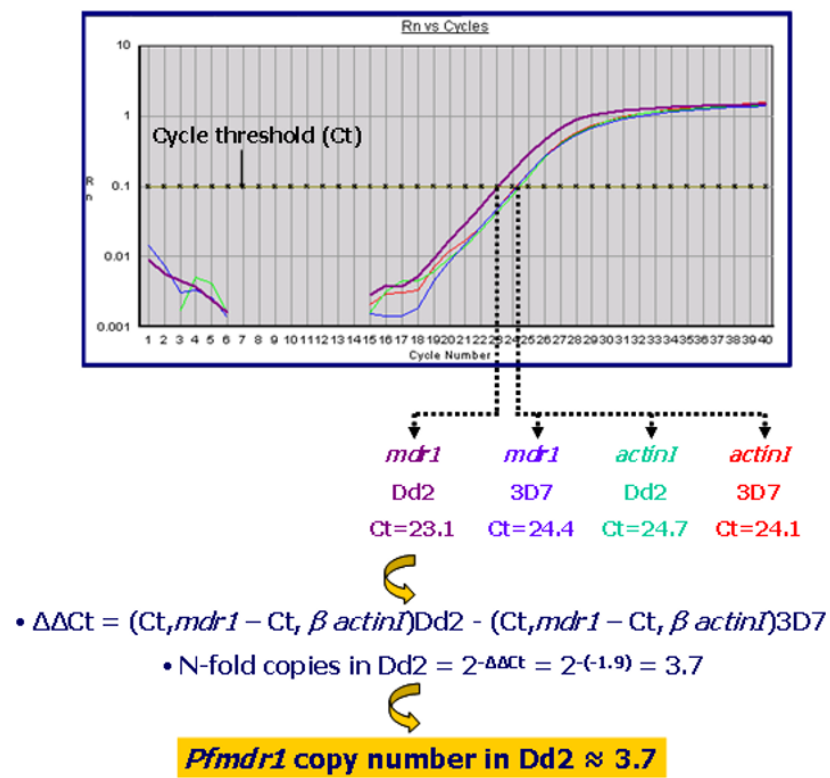

Figure 2

Typical results of estimation of pfmdrl copy number in $P$. falciparum $\mathrm{Dd} 2$ relative to 3D7.

The $\Delta \Delta \mathrm{Ct}$ calculation for the relative quantification of target was used as follows ${ }^{\Delta \Delta} \mathrm{Ct}=(\mathrm{Ct}$, target gene $-\mathrm{Ct}, P f-\beta$ actin1 $) \chi-(\mathrm{Ct} \text {, target gene }-\mathrm{Ct}, P f-\beta \text {-actin } 1)_{\mathrm{y}^{\prime}}$ where $\chi=$ unknown sample and $\mathrm{y}=P$. falciparum $3 \mathrm{D} 7$. After validation of the method, results for each sample were expressed in $\mathrm{N}$-fold changes in $\chi$ target gene copies, normalized to $P f-\beta$-actin-1 relative to the copy number of the target gene in $P$. falciparum 3D7, according to the following equation: amount of target $=2^{-\Delta \Delta \mathrm{Ct}}[16]$. A minimum of two experiments was carried out for each gene and sample. At each experiment, each individual sample was run in triplicate wells and the Ct of each well was recorded at the end of the reaction. The average and standard deviation (SD) of the three Cts was calculated and the average value was accepted if the SD was lower than 0.38 [17]. Results for each sample were expressed as the $\mathrm{N}$-fold copy number of a given gene relative to $P$. falciparum 3D7, by calculating the geometric mean between the two experiments. Assays were repeated if amplification curves did not reflect exponential kinetic parameters or if the $\mathrm{N}$-fold copy number of a given gene was lower than 0.7 or higher than 1.3. In cases where $\mathrm{N}$-fold was comprehended between those values $(0.7<\mathrm{N}$-fold $<1.3)$, it was accepted that the test sample harboured a single copy of the target gene, i.e., $\mathrm{N}$-fold $=1$.

\section{Determination of real-time PCR efficiencies}

For the $\Delta \Delta \mathrm{Ct}$ calculation to be valid, two important parameters must be considered beforehand. First, the efficiency of a given PCR amplification must be close to $100 \%$, and second, the relative efficiency must be opti- 
Table 3: Estimation of pfmdrl copy number in $P$. falciparum Dd2 relative to 3D7, resulting from the analysis of 20 independent experiments

\begin{tabular}{ccccc}
\hline Previously reported & \multicolumn{4}{c}{ Observed in present work } \\
\hline & Mean & Min. & Max. & SD \\
4 & 3.7 & 3.2 & 4.5 & 0.68 \\
\hline
\end{tabular}

mal, that is, the amplification efficiencies of the target and reference genes must be approximately equal [16]. In order to determine PCR efficiencies for each gene, $P$. falciparum 3D7 genomic DNA was diluted in serial 10-fold ranges and the $\mathrm{Ct}$ value at each dilution was measured. A curve was then constructed for each gene from which efficiency was determined. Real-time PCR efficiencies (E) were calculated from the given slopes, according to the equation: $\mathrm{E}=10^{(-1 / \text { slope })}-1 \times 100[10]$, where $\mathrm{E}=100$ corresponds to $100 \%$ efficiency [12]. PCR reactions where the amplicon doubles at every cycle have an optimal efficiency of $100 \%$ compared to reactions where no amplification occurs and efficiency is $0 \%$.

To measure relative efficiency, amplifications were performed on the same diluted samples, using primers for the reference (Pf- $\beta$-actin 1$)$ and the target genes. The average $\mathrm{Ct}$ was calculated for both reference and target genes and the $\Delta \mathrm{Ct}(\mathrm{Ct}$, target gene - $\mathrm{Ct}, P f-\beta$-actin 1$)$ was determined. Plots of the log DNA dilution versus $\Delta \mathrm{Ct}$ were made. If the absolute value of the slope was close to zero $(\mathrm{m}<0.1)$, the efficiencies of the target and reference genes were similar, and thus the $\Delta \Delta \mathrm{Ct}$ calculation could be applied.

\section{Results and discussion Reaction efficiencies and validation of the assay}

Predicted coding sequences obtained for each gene were used to design internal oligonucleotide primers for application in real-time PCR (Figure 2 and Table 3) as described in Materials and Methods section. Using these primers, real-time PCRs were first optimised for each gene by varying both primer and PCR reagent concentrations,
After a number of rounds of optimisation for each gene individual PCR efficiencies (E) neared 100\% in all cases (data not shown). This was also the case for the relative efficiencies between each target gene and Pf- $\beta$-actin1. Therefore, there was no need for efficiency correction. Figure 1 depicts an example assay for the calculation of relative PCR efficiency.

To further test the validity of the assays, the copy number of the Pfmdr1 gene was compared between the laboratory clones P. falciparum 3D7 and P. falciparum Dd2. The clone 3D7 harbours one copy of the gene while the multidrug-resistant resistant line, Dd2, a derivative of W2mef, contains 4 copies. [3,18]. After ensuring optimal conditions for the pfmdr1 assay, the N-fold copy number of Dd2 in comparison to 3D7 was evaluated in twenty independent experiments, as depicted in an example in Figure 2 . We note that this system was not directly compared to that reported in references 10 and 11 and in addition, that it would have been more informative to further validate the assay with other Pfmdr1 multicopy strains. Nevertheless, the present observations indicated that the assay was robust enough to ensure validation (Table 3 ).

\section{Testing the methods on genomic DNA of natural parasite} populations

After optimization of protocols for all different genes the assays were deployed on genomic DNA extracted from confirmed $P$. falciparum infections obtained from eight isolates of the Democratic Republic of São Tomé and Princípe. Parasite densities were determined in Giemsastained blood smears and recorded as the number of parasites/ $\mu \mathrm{l}$ of blood, assuming an average leukocyte count of $8,000 / \mu \mathrm{l}$ (all smears were examined against 500 leucocytes prior to be declared negative). Parasite densities in these isolates ranged from 2,500 to 500,000 parasites $/ \mu \mathrm{l}$. For measuring the copy number of each gene in each sample, two microlitres of undiluted genomic DNA were used as template for RT-qPCR regardless of parasitaemia. Although it was observed that lower parasite densities caused small shifts of amplification curves to the right (reflecting higher $\mathrm{Ct}$ values), that did not influence the

Table 4: Estimated gene copy numbers in eight $P$. falciparum field-isolates from the DRSTP

\begin{tabular}{|c|c|c|c|c|c|c|c|c|c|}
\hline \multirow[t]{2}{*}{ Parasite } & \multicolumn{9}{|c|}{ Copy number relative to $P$. falciparum 3D7 } \\
\hline & Pfmdrl & Pfatp6 & pftctp & $p f g p x$ & pfgr & pfgst & PfsodI & Pftrxl & Pftrx2 \\
\hline $\mathrm{Dd} 2$ & 3.7 & 1 & 1 & 1 & I & 1 & 1 & 1 & 1 \\
\hline $\begin{array}{l}\text { S. Tomé } \\
\text { strains }\end{array}$ & I & I & 1 & 1 & I & I & 1 & 1 & 1 \\
\hline
\end{tabular}

Legend: Eight strains from the islands of São Tomé and Princípe were tested (coded ST060, ST073, ST045, ST0I3, ST065, ST058 and ST035). For simplification, results are expressed in a single row, since all parasites harboured one copy of the studied genes.

in order to obtain optimal efficiencies (data not shown). outcome of relative kinetic parameters, since data was 
normalized against the $\beta$-actin1 gene (data not shown). These experiments showed, however, that there was no amplification in any of the genes among all isolates analysed (Table 4).

\section{Conclusion}

Protocols were developed to estimate copy numbers of nine putative drug resistance candidate genes in $P$. falciparum. These were initially validated by accurate measure of previously known number of copies of the $p f m d r 1$ gene in the drug-sensitive strain $P$. falciparum 3D7 and the multi-drug resistant Dd2. Subsequently, protocols were developed for 8 other genes, which were successfully applied to DNA obtained from field isolates of P. falciparum collected in the DRSTP. In these particular case, however, all isolates harboured a single copy of the genes studied (Table 4).

The methodology was shown to be sensitive and specific allowing copy number estimations using template DNA extracted with chelex resin from filter paper blood spots, independent of sample parasitaemia. Since all Standard Operating Procedure were designed to function under similar PCR temperatures and reagent concentrations, multiple genes may be analysed in a 96-well optical plate, significantly increasing throughput. The method bypasses the need of gene-specific probes since it relies on SYBR Green I detection and can, thus, be adapted to any given gene provided optimal experimental conditions are assured. As long as primers are properly constructed, most genes are easily and reliably detected with the less cumbersome and less expensive SYBR green I detection method.

Since the methodology relies on relative quantification, it by-passes the need to measure DNA concentration in any given sample. Although a quantification of target genes in genomic DNA is reported, these methods should be equally useful to measure gene expression using cDNA as template, since all primers are located in exons, although it is advisable that PCR efficiencies are calculated and optimized if required, prior to such experiments.

For all reasons cited above, these protocols may be a highly useful tool for high throughput large scale epidemiological assays or laboratory studies.

\section{Authors' contributions}

IDF carried out most of the experimental procedures and contributed for the elaboration of the manuscript. VEdR and PC conceived the study, participated in its design and co-ordination and were involved in phases of the experimental work.

\section{Acknowledgements}

This study is part of the research conducted by RESMALCHIP, a European Research Consortium, contract QLK2-CT-2002-01503. Virgílio E. do

Rosário and Pedro Cravo were funded by the Instituto de Higiene e Medicina Tropical/UNL, Portugal. Isabel D. Ferreira was funded by RESMALCHIP (contract QLK2-CT-2002-01503). We thank the staff of the Centro Policlínico de Saúde de Água Grande, city of São Tomé.

\section{References}

I. Wongsrichanalai C, Pickard AL, Wernsdorfer WH, Meshnick SR: Epidemiology of drug-resistant malaria. Lancet Infect Dis 2002 , 2:209-2। 8 .

2. Cravo P, Culleton R, Afonso A, Ferreira ID, do Rosário VE: Mechanisms of drug resistance in malaria: current and new challenges. Anti-infective Agents in Medicinal Chemistry 2006, 5:63-73.

3. Cowman AF, Galatis D, Thompson JK: Selection for mefloquine resistance in Plasmodium falciparum is linked to amplification of the pfmdrlgene and cross-resistance to halofantrine and quinine. Proc Natl Acad Sci USA 1994, 9 I: I I 43- I I 47.

4. Ginsburg H: Should chloroquine be laid to rest? Acta Trop 2005, 96:16-23.

5. Meierjohann S, Walter RD, Muller S: Regulation of intracellular glutathione levels in erythrocytes infected with chloroquinesensitive and chloroquine-resistant Plasmodium falciparum. Biochem / 2002, 368:761-768.

6. Dubois VL, Platel DF, Pauly G, Tribouley-Duret J: Plasmodium berghei: implication of intracellular glutathione and its related enzyme in chloroquine resistance in vivo. Exp Parasitol 1995, 81: I17-124.

7. Srivastava P, Puri SK, Kamboj KK, Pandey VC: Glutathione-Stransferase activity in malarial parasites. Trop Med Int Health 1999, 4:25I-254.

8. Efferth T: Mechanistic perspectives for $1,2,4$ trioxanes in anticancer therapy. Drug Resist Updat 2005, 8:85-97.

9. Uhlemann AC, Cameron A, Eckstein-Ludwig U, Fischbarg J, Iserovich P, Zuniga FA, East M, Lee A, Brady L, Haynes RK, Krishna S: A single amino acid residue can determine the sensitivity of SERCAs to artemisinins. Nat Struct Mol Biol 2005, I 2:628-629.

10. Pickard AL, Wongsrichanalai C, Purfield A, Kamwendo D, Emery K, Zalewski C, Kawamoto F, Scott Miller R, Meshnick SR: Resistance to antimalarials in southeast Asia and genetic polymorphisms in pfmdrl. Antimicrob Agents Chemother 2003, 47:24I8-2423.

II. Price RN, Uhlemann AC, Brockman A, McGready R, Ashley E, Phaipun L, Patel R, Laing K, Looareesuwan S, White NJ, Nosten F, Krishna S: Mefloquine resistance in Plasmodium falciparum and increased pfmdrl gene copy number. Lancet 2004, 364:438-447.

12. Plowe CV, Djimde A, Bouare M, Doumbo O, Wellems TE: Pyrimethamine and proguanil resistance-conferring mutations in Plasmodium falciparum dihydrofolate reductase: polymerase chain reaction methods for surveillance in Africa. Am J Trop Med Hyg 1995, 52:565-568.

13. Plasmodium falciparum GeneDB [http://www.genedb.org/ genedb/malaria/blast.jsp]

14. Rozen S, Skaletsky H]: Primer3 on the WWW for general users and for biologist programmers. In Bioinformatics Methods and Protocols: Methods in Molecular Biology Edited by: Krawetz S, Misener S. Humana Press, Totowa, NJ; 2000:365-386.

15. Oligonucleotide Properties Calculator [http:// www.basic.northwestern.edu/biotools/oligocalc.html]

16. Livak KJ, Schmittgen TD: Analysis of relative gene expression data using real-time quantitative PCR and the $2^{-}-\Delta \Delta \mathrm{Ct}$ method. Methods 200I, 25:402-408.

17. Pfaffl MW: A new mathematical model for relative quantification in real-time RT-PCR. Nucleic Acids Res 200I, 29:2002-2007.

18. Wellems TE, Panton LJ, Gluzman IY, Rosário VE, Gwadz RW, Walker-Jonah A, Krogstad DJ: Chloroquine resistance not linked to $m$ dr-like genes in a Plasmodiumfalciparum cross. Nature 1990, 345(6272):253-255. 